\title{
Sobre as contribuições das análises culturais para a formação dos professores do início do século XXI
}

\section{On the contributions of cultural analysis to teachers' training of the beginning of the $X X I$ century}

\author{
Marisa Vorraber Costa ${ }^{1}$
}

\begin{abstract}
RESUMO
O artigo discute as repercussões, no trabalho docente e na formação de professores, das profundas e marcantes transformações culturais verificadas nos últimos sessenta anos. Inicia com breves considerações acerca da condição pós-moderna, das análises culturais contemporâneas e suas filiações teóricas. Em seguida, trata das conexões entre cultura, pedagogias, escola e sujeitos escolares. Para dotar o trabalho de força argumentativa, apresenta uma amostra de estudos que realizam análises de fenômenos culturais contemporâneos, expondo e discutindo suas implicações para a educação e, consequentemente, para a formação de professores. Nessa direção, o artigo aborda o que pode ser considerado como contribuições das análises realizadas na conjunção dos Estudos Culturais com a Educação para a ampliação do âmbito de reflexões no campo da Formação de Professores.

Palavras-chave: formação de professores; formação de professores e estudos culturais; trabalho docente e estudos culturais; educação e análises culturais.
\end{abstract}

\footnotetext{
ABSTRACT

The article discusses the repercussions at teaching work and the formation of teachers, under deep and remarkable cultural changes occurred in

1 Universidade Luterana do Brasil, Brasil/Universidade Federal do Rio Grande do Sul, Brasil. Pesquisadora do Conselho Nacional de Desenvolvimento Científico e Tecnológico - CNPq. Artigo subsidiado por resultados de pesquisas realizadas na condição de bolsista de produtividade.
} 
the last sixty years. It starts by presenting brief considerations about the postmodern condition, the contemporary cultural analysis and their theoretical affiliations. After that, it discusses the connections among culture, pedagogies, school and school students. In order to provide the task with argumentative power, it presents a sample of researches that carry out analysis of contemporaneous cultural phenomena, exposing and discussing their implications for education and, consequently, to teachers'development. In this sense, the article discusses what can be considered as contributions from analysis performed in Cultural Studies conjunction with Education in order to broaden reflections in the Teacher's formation field.

Keywords: teachers' formation; teachers' formation and cultural studies; teachers' work and cultural studies; education and cultural analysis.

\section{Situando}

Os últimos sessenta anos vêm sendo marcados por profundas e importantes transformações culturais, que incidem nas formas de vida das sociedades, com intensas e ruidosas repercussões no trabalho docente. Sem dúvida, a atenção a essas mudanças e a preparação adequada para equacioná-las tem sido imperativas para o campo da Formação de Professores e um desafio para suas propostas. Nessa direção, este artigo aborda o que vislumbro como contribuições das análises realizadas na conjunção dos Estudos Culturais com a Educação para a ampliação do âmbito de reflexões no campo da Formação de Professores.

Início com breves considerações acerca das análises culturais contemporâneas e suas filiações teóricas. Em seguida, procuro tratar das conexões entre cultura, pedagogias, escola e sujeitos escolares. Para dotar o trabalho de força argumentativa, dedico-me a apresentar uma breve amostra de estudos que realizam análises de fenômenos culturais contemporâneos, expondo e discutindo suas implicações para a educação e, consequentemente, para a formação de professores.

Para a tarefa a que me proponho, algumas advertências se fazem necessárias. Em primeiro lugar, seguindo normas relativas à extensão do texto, abdico de apresentar uma cadeia mais ampla de argumentações para delinear tanto o terreno analítico quanto o programa de investigação em que tenho me movimentado nos últimos anos. O que faço são alguns recortes - segundo o critério da utilidade e da operacionalidade - para esboçar um panorama mais ou menos adequado e próprio ao meu intento. Em segundo lugar, quanto aos estudos que compõem a amostra à título de argumentação, opero uma seleção 
arbitrária, estratégica e interessada, referindo-me às pesquisas com as quais estive diretamente envolvida.

\section{Sobre análises culturais e inspiração teórica}

A segunda metade do século XX assistiu a emergência de análises culturais alinhadas em contundente crítica à teoria cultural vigente, assentada sobre concepções inspiradas na tradição arnoldiana ${ }^{2}$ de cultura, dominante desde os meados do século XIX. Entre muitos outros focos, as novas análises dedicam-se centralmente à crítica das distinções entre alta e baixa cultura e ao fortalecimento das produções e das manifestações culturais populares. A literatura especializada tem apontado para o surgimento de estudos com esse teor, nesse período, esboçados em várias partes do mundo, inclusive América Latina, África e Ásia. Porém, a movimentação com visibilidade mais proeminente parece ter sido a dos Cultural Studies, na Inglaterra, entre nós conhecida como Estudos Culturais ${ }^{3}$.

Seguindo a linha de periodização traçada por historiadores e intelectuais das humanidades, os meados do século XX corresponderiam frouxamente ao que se convencionou chamar de pós-modernidade. Sem entrar nas controvertidas polêmicas acerca das pretensões de ruptura e superação do moderno, a pós-modernidade teria marcado uma indiscutível e nada negligenciável mudança de perspectiva em que os freios institucionais fazem-se em pedaços, a razão moderna universal e totalizante mostra-se exaurida em suas pretensões de verdade, e as grandes ideologias e estruturas socializantes perdem gradativamente a autoridade. Obviamente, tais transformações não ocorreram abruptamente, e seus contornos esboçaram-se em um longo processo.

Raymond Williams, um dos fundadores dos Cultural Studies britânicos e considerado um dos expoentes da teoria cultural contemporânea, nos livros Cultura e Sociedade ${ }^{4}$ The long Revolution ${ }^{5}$ analisa as transformações da vida

2 Denominação alusiva ao principal teórico da "tradição da cultura e da civilização", Mathew Arnold (séc. XIX).

3 Uma discussão aprofundada acerca dessa denominação e dos estudos encaixados nessa vertente analítica pode ser encontrada em Costa, Hessel e Sommer (2003), cf. ref. bibliog.

4 Título original Culture and Society (1958), traduzido para o português por Anísio Teixeira, Leônidas Hegenberg e Octanny da Mota, publicado no Brasil em 1969.

5 Sem tradução localizada para o português, esse livro, publicado na Inglaterra em 1961, prossegue a análise iniciada em Cultura e Sociedade. 
social desde o final do século XVIII até os anos 1960. Para fazer uma descrição, análise e interpretação da "herança intelectual, imaginativa e sentimental" recebida pela geração dos meados do século XX, recorre aos autores mais significativos na produção do que ele chama de "revolução cultural", trilhada pela cultura ocidental de 1780 a 1950 . O eixo de sua argumentação são as transformações no conceito de cultura, que analisa quando considera a teoria da cultura como "a teoria das relações entre os elementos de um sistema geral de vida". Williams (1969) afirmou, lá nos meados do século XX, que vivíamos em uma "cultura em expansão", cuja análise e interpretação suscitavam mais lamentações e desencantos do que um trabalho árduo de interpretação das grandes e profundas transformações pelas quais a humanidade vinha passando. Os indícios da emergência de formas culturais novas, complexas e ainda de difícil inteligibilidade desafiaram-no a tentar compreender e explicar os mistérios desses novos tempos.

Essa mutação cultural, cujo processo de gestação e prenúncios são descritos e interpretados por Williams como uma "longa revolução", começa a ser experimentada de forma intensa e contundente a partir da segunda metade do século XX, no pós-guerra, e percorre os amplos e variados domínios da existência humana, implicando transformações de diferentes ordens: tecnológica, econômica, social, filosófica, científica, artística, cultural e muitas outras. Essa movimentação forjou novos modos de viver e novas formas de pensar. No domínio intelectual, pode-se dizer que uma matriz de inteligibilidade inspirada nesse espírito dos novos tempos passa a orientar boa parte dos estudos e pesquisas, especialmente no campo das ciências humanas e sociais.

De uma maneira geral, a intrigante condição existencial que nos envolve hoje é atribuída, preponderantemente, mas não exclusivamente, à avassaladora proeminência das novas tecnologias e à consequente instauração de uma cultura midiática de alcance planetário. Segundo muitos autores, é nossa própria humanidade que estaria sendo transformada. Pierre Lévy (1996, p. 11) faz alusão a "um coletivo pensante homens-coisas, coletivo dinâmico povoado por singularidades atuantes e subjetividades mutantes", uma ecologia cognitiva, imensa maquinaria do fazer em que o sujeito que pensa e o coletivo cosmopolita, se confundem. Poderíamos então afirmar que está em andamento a constituição de uma nova gramática cultural, e é no interior dela que se desenham as tentativas para nos movimentarmos nos meandros de suas prescrições normativas, morfologias, léxico, sintaxes e semântica.

Desde Raymond Williams (1961, 1969), passando por Fredric Jameson (1996), David Harvey (1993), Andréas Huyssen (1992), Zigmunt Bauman (1998, 1999, 2001, 2007, 2008), Richard Sennet $(2002,2006)$ e outros, vários autores vêm mencionando a emergência de uma profunda transformação na "estrutura 
do sentimento". Muitos autores concordam que na lenta transformação cultural que atravessa o século XX está implicada uma mudança da sensibilidade. O conceito introduzido por Williams tem sido fulcral para se procurar compreender as novas formas de práticas e de hábitos sociais e mentais em conjunção com novas formas de organização e de produção econômica, que surgem acopladas à verdadeira revolução cultural verificada nos modos de produção capitalistas. Jameson (1996) aponta o entrelaçamento entre economia e cultura num processo de interação recíproca, num circuito infinito de realimentação, constituindo essa mútua aderência por si só um fenômeno pós-moderno. É nesse sentido que se tem afirmado que o mundo pós-moderno produz não apenas uma economia, um modo de produção e uma sociedade muito peculiares, como constitui sujeitos de um certo tipo, pessoas pós-modernas. Segundo o autor, opera-se uma "[...] prodigiosa operação de reescritura - que pode levar a perspectivas totalmente novas a respeito da subjetividade e também do mundo objetivo [...]" (JAMESON, 1996, p.18).

Esse estado da cultura, ao qual Harvey (1993) e Lyotard (s/d) referem-se como "condição pós-moderna", aporta consequências importantes para a educação, área intensamente marcada pelo que tem sido identificado apropriadamente como virada pós-moderna e virada cultural. Tais expressões surgiram acopladas à movimentação filosófica identificada como virada linguística, compartilhada por boa parte daqueles que se aproximam das visões pós-modernas. Grosso modo, pode-se afirmar que diz respeito à concepção em que os discursos estão inexoravelmente implicados naquilo que as coisas são. As sociedades e culturas em que vivemos são dirigidas por poderosas ordens discursivas que regem o que deve ser dito e o que deve ser calado e os próprios sujeitos não estão isentos desses efeitos. A linguagem, as narrativas, os textos não apenas descrevem ou falam sobre as coisas, ao fazer isso instituem as coisas, inventando sua identidade. O que temos denominado "realidade" é o resultado desse processo no qual a linguagem ${ }^{6}$ tem um papel constitutivo. É nesse sentido também que a cultura tem um papel instituinte, identificado no campo epistemológico como virada cultural (HALL, 1997). De acordo com visões foucaultianas, nisso está implicado o poder; não um poder maligno, dissimulado, que emana de uma única fonte, mas um poder produtivo, disseminado, capilar e circulante. Um poder que se exerce na forma de uma "vontade de saber" que é também "vontade de poder". Quando se descrevem, explicam, desenham ou contam coisas, quando variadas textualidades falam sobre pessoas, lugares ou práticas, esses

6 Entende-se, aqui, linguagem, não apenas como forma de comunicação oral, ou como texto letrado. Linguagem diz respeito a toda forma de expressão, de manifestação que atribui sentido e, assim, inventa, cria algo. 
estão sendo inventados conforme a lógica, o léxico e a semântica vigentes no domínio que produz o discurso. Nesse sentido, Hall (1997) refere-se também a política cultural da representação.

Tais visões e concepções vêm abalando fortemente o campo da pesquisa educacional. Os estudos com caráter prescritivo e normativo têm sido amplamente problematizados face à sua presumível incapacidade para dar conta da experiência humana instável, mutante, eivada de exigências emergentes e constantemente renovadas. Por sua vez, as investigações com caráter mais reflexivo e focos pouco comuns na área da Educação adentram o espaço investigativo eivadas de ceticismo e críticas. É sobre isso que me deterei na próxima sessão.

\section{Sobre conexões entre cultura, pedagogias, escola e sujeitos escolares}

Na Introdução do livro Borders crossings: cultural workers and the politics of education, Henry Giroux (1992) ${ }^{7}$ anuncia mudanças em sua postura política e teórica, declarando não acreditar mais que uma educação crítica possa ficar confinada nas escolas, e tampouco que "[...] a pedagogia, como forma de produção política, moral e social, possa ser tratada primordialmente como um problema de escola." (GIROUX, 1992, p.11). Esclarece ainda que apesar de nunca ter considerado que apenas as escolas pudessem mudar a sociedade, havia investido sua energia teórica e ação política nesses locais. Agora, contudo, percebera muitas coisas, entre elas, "a limitação que o conservadorismo prevalecente exerce na composição do currículo e na visão da maioria das faculdades de educação [...]" (GIROUX, 1992, p.11). Isso, juntamente com sua reinterpretação do próprio significado de pedagogia, vista agora como prática social e de produção cultural implicada na política cultural que envolve conhecimentos, desejos, valores e práticas, fez com que estendesse suas preocupações para o âmbito social mais amplo, em busca de uma pedagogia radical como política cultural. Mais adiante nesse livro, descreve a pedagogia como "uma tecnologia do poder, da linguagem e da prática que produz e legitima formas de regulamentação moral e política, que constrói e oferece aos seres humanos visões particulares de si próprios e do mundo" (GIROUX, 1992, p. 98).

Giroux (2003) salienta em obra posterior que as teorias educativas conservadoras geralmente consideram que o conhecimento é a realização da tradição

7 Obra traduzida para o português em 1999 com o título Cruzando as fronteiras do discurso educacional: novas políticas em educação. Menciono no texto a obra original de 1992, para enfatizar que quase vinte anos nos separam do surgimento dessa análise. 
(ocidental) e a pedagogia uma prática do processo de transmissão. Assim concebida, a pedagogia parece estar exclusivamente vinculada aos conteúdos das disciplinas escolares e, portanto, associada aos padrões e valores dominantes em uma sociedade. Contudo, não é isso que observamos hoje, e ele próprio dedica grande parte de seu esforço investigativo na tentativa de mostrar as pedagogias em operação nos variados territórios da cultura.

Compartilho de seu entendimento, uma vez que vivemos hoje uma era pautada por significados provisórios, incertezas e indeterminações, cenário em que as práticas antes privativas de certos espaços institucionais, como a pedagogia, encontram-se desterritorializadas. Desenham-se crescentemente novos contributos teóricos para se pensar a pedagogia como uma prática cultural que ultrapassa amplamente os limites estritos de instituições como, por exemplo, escola, família e igreja. Uma contribuição dos Estudos Culturais em Educação tem sido a possibilidade de se abordar de forma mais ampla, complexa e plurifacetada a educação, os processos pedagógicos, os sujeitos implicados, as fronteiras construídas pelas ordens discursivas dominantes. Pode-se dizer que há uma ressignificação do campo pedagógico em que questões culturais como identidade, diferença, discurso e representação são convertidos em foco preferencial.

Costa, Silveira e Sommer (2003, p. 56), no artigo em que analisam as conexões entre EC e pedagogia, apontam como contribuições mais importantes dos Estudos Culturais em Educação as que têm possibilitado:

[...] a extensão das noções de educação, pedagogia e currículo para além dos muros da escola; a desnaturalização dos discursos de teorias e disciplinas instaladas no aparato escolar; a visibilidade de dispositivos disciplinares em ação na escola e fora dela; a ampliação e complexificação das discussões sobre identidade e diferença e sobre processos de subjetivação. Sobretudo, tais análises têm chamado a atenção para novos temas, problemas e questões que passam a ser objeto de discussão no currículo e na pedagogia .

Mais adiante, nesse mesmo texto, indicam alguns focos preferenciais, reunidos no que chamam de vertentes de análises dentro desse campo. $\mathrm{Na}$ primeira vertente mencionam: 
[...] questões, discursos e artefatos que, tradicionalmente tidos como pedagógicos, são ressignificados: livros didáticos, cartilhas, legislações educacionais, revistas pedagógicas, livros de formação pedagógica para professores, programas e projetos educativos, a própria seriação escolar, a ciclagem e as classes de progressão, a arquitetura escolar. Práticas escolares como a da merenda, da avaliação, ou dos cuidados na educação infantil, entre outras, são problematizadas e constituídas como objetos de estudo sob uma ótica cultural, oportunizando seu esquadrinhamento e análise como produtoras de significados, como imersas em redes de poder e verdade, em discursos circulantes, através dos quais se legitimam determinadas representações de crianças, de menino e de menina, de estudante, de professores e professoras, de trabalho docente, de alfabetismo, de determinados componentes curriculares e de educação (COSTA; SILVEIRA; SOMMER, 2003, p. 56).

Outra vertente é aquela que discute a questão das identidades e que aparece em "trabalhos que problematizam a heterogeneidade e hibridação de algumas delas, como as de gênero, de índio, de surdo" (COSTA; SILVEIRA; SOMMER, 2003, p. 57), assim como identidades regionais (o gaúcho, indígenas amazônicos, etc.), novas identidades (motobói (PROTAS, 2009), sem-terra (COSTA, 2009), juventude rave (BORTOLAZZO, 2010) internautas, etc. $)^{8}$. Nelas, a tendência que emerge, sem negligenciar a visibilização de pedagogias culturais, são os confrontos entre local e global, entre discursos tradicionais e aqueles da contemporaneidade midiática, questões centrais no panorama sociocultural da atualidade, imbricados diuturnamente nos desafios educacionais e no trabalho educativo.

Nesse trabalho de Costa, Silveira e Sommer (2003) são ainda mencionadas a vertente mais centralmente voltada para as pedagogias culturais e outra para as articulações dos Estudos Culturais com a escola. Tratarei delas a seguir neste texto.

Como se pode constatar, mais recentemente, já são numerosos os estudos no Brasil (e no exterior também) que, inspirados nas teorizações do que se convencionou denominar de vertente pós-estruturalista, têm apontado para uma intensa proliferação de formas e intenções pedagógicas assim como de modos de ser sujeito e de identidades.

Conforme já mencionei, um dos conceitos fecundos para se pensar a educação nesses novos tempos perpassados pela condição pós-moderna tem sido o de pedagogias culturais. Embora seja um termo tautológico se tomado

8 Uma expressiva produção relativa a tais focos de pesquisa pode ser localizada em teses e dissertações dos programas de Pós-Graduação em Educação da Universidade Federal do Rio Grande do Sul (UFRGS), Brasil e da Universidade Luterana do Brasil (ULBRA). 
fora do âmbito das análises culturais contemporâneas - uma vez que seria difícil pensar-se em alguma pedagogia que não seja produzida pela cultura, sendo, portanto, culturais todas as pedagogias - o conceito tem sido útil para referirmo-nos àquelas práticas culturais extraescolares que participam de forma incisiva na constituição de sujeitos. Utilizado por autores que vêm se dedicando à investigação da produtividade da cultura pós-moderna predominantemente midiática, a expressão é empregada, por exemplo, nas análises já mencionadas de Giroux (1999), Steinberg e Kincheloe (2001, p. 14), que definem como áreas pedagógicas "aqueles lugares onde o poder é organizado e difundido, incluindo-se bibliotecas, TV, cinemas, jornais, revistas, brinquedos, propagandas, videogames, livros, esportes, etc.", como também em estudos desenvolvidos no Brasil por Costa $(2009,2002)$ e outros autores do campo dos Estudos Culturais.

Nesse panorama de transformação nas concepções de educação, política, cultura e pedagogia, os Estudos Culturais têm se apresentado como um campo fecundo de análise da produtividade das pedagogias culturais na constituição de sujeitos, na composição de identidades, na disseminação de práticas e condutas, enfim, no delineamento de formas de ser e viver na contemporaneidade. Parte significativa das organizações que hoje educam crianças e jovens (e adultos também) não são educacionais, e sim comerciais. O currículo cultural que colocam em operação não está preocupado com a melhoria da sociedade, com o aprimoramento de suas práticas e instituições e com o bem comum; as corporações empresariais de hoje estão interessadas na convocação, formação e enredamento de sujeitos em suas teias de mercantilização e consumo ${ }^{9}$. Colocam em operação estratégias que acionam sedução, fascínio e prazer, visando ampliar seus ganhos individuais e seu poder nas economias globalizadas do novo capitalismo. As professoras do admirável mundo do novo capitalismo, tal como nomeado por Sennet (2006), são as grandes corporações empresariais e seus sofisticados complexos que combinam marketing e mídia em fórmulas inescapáveis de enredamento. Como argumentam Steinberg e Kincheloe (2001, p. 15), "A pedagogia cultural corporativa 'fez seu dever de casa' - produziu formas educacionais de um incontrolável sucesso quando julgadas com base em seu intento capitalista.". Acionando fantasia e desejo, criou-se uma perspectiva cultural que "mescla ideologias de negócios e valores de livre mercado" (STEINBERG; KINCHELOE, 2001, p.15). Tal movimentação transformou também a cultura em recurso (YÚDICE, 2004), e a escola não escapou disso. Costa e

9 Entende-se aqui o consumo em concepções atualizadas. Harvey (1993) fala de uma nova concepção que surge com o declínio do fordismo e a emergência da acumulação flexível. Jameson (1996) considera o consumo uma "dominante cultural" e Bauman situa-o com referência à sociedade de consumidores. Todas aludem a algo distinto do consumo da sociedade de produtores. Ver a esse respeito Bauman $(1999,2008)$ e Costa (2009a). 
Momo (2009) abordam esse fenômeno contemporâneo no artigo intitulado $A$ conveniência da escola.

O trabalho de pesquisa em que tenho me concentrado nos últimos anos (COSTA 2004, 2007) investiga a entrada e a presença da cultura pós-moderna na escola, assim como sua produtividade na constituição de sujeitos e na conformação das práticas pedagógicas. Nessas pesquisas delineia-se a presença da mídia, especialmente da televisão, em uma dimensão assustadora. Os artefatos postos em circulação em suas redes, e seus efeitos em termos de proliferação de preferências, desejos, estilos, modos de ser, condutas é inteiramente surpreendente e superou todas as minhas suposições anteriores. Telenovelas, desenhos animados, seriados, filmes infantis e infanto-juvenis, shows e videoclips, peças publicitárias e produtos de todo o tipo dirigidos às crianças e jovens, compõem o conjunto aparentemente mais poderoso desse arsenal. Mas também outdoors, celulares, DVDs, jogos eletrônicos, telões digitais fazem a sua parte no imenso aparato techno de comunicação e entretenimento, impregnado de discursos, práticas e táticas de convocar sujeitos. A cultura midiatizada opera dispositivos poderosos com profundas repercussões na reconfiguração de todas as instâncias e dimensões da condição humana nas sociedades contemporâneas. Crianças e jovens escolares forjam as experiências que vão dar rumo a suas vidas no interior de uma nova ordem, definida principalmente em termos de uma economia liberta de embaraços políticos, éticos e culturais.

É no panorama cultural e teórico cujos traçados procurei brevemente esboçar até aqui, e no âmbito das pesquisas recém mencionadas, que se desenvolveram os estudos que pretendo apresentar como uma contribuição para se pensar a educação básica, os currículos e os sujeitos escolares desses tempos e, em consequência, para se pensar a formação de professores. Entendo que as análises realizadas mostram um pouco desse conjunto da experiência contemporânea, crescentemente marcada pela instantaneidade, volatilidade, efemeridade e descartabilidade, típicas da vida cotidiana comum dos consumidores pósmodernos - crianças, jovens e adultos.

O que observo é que ao focalizar o interior da escola fui recorrentemente levada a olhar para fora dela, para a cultura e suas operações de controle social, de governo das subjetividades em sua refinada versão de uma governamentalidade neoliberal.

As tecnologias da comunicação e da informação vêm contribuindo para a proliferação, ampla circulação e consumo de textos culturais populares, que exercem um enorme fascínio sobre as pessoas. Na promoção desse fascínio estão implicados desejos, sonhos, sedução, modelos a serem imitados, aptidões a serem adquiridas. Sobretudo, como mostram os estudos e reflexões de autores como Bauman (2007), Garcia-Canclini (2006), Beatriz Sarlo (1997) e 
tantos outros, nas sociedades pós-modernas as pessoas são vistas primariamente como consumidoras, e grande parte das ações de governamentalidade estão hoje voltadas para orientar o desejo, não na forma estrita de regulação, mas de incentivo à fantasia, ao gosto, à autoexpressão. E já não se trata de consumir em uma acepção usual da palavra, são novas formas de consumo que poderiam ser mais bem descritas como "comprismo", desejo de adquirir de tudo - imagens de si, sonhos, objetos - para em seguida descartar e substituir. Bauman (2008) trata, inclusive, da "transformação das pessoas em mercadoria".

Parece que a dinâmica das sociedades orientadas para o consumo vem produzindo uma transformação disseminada, que ocorre na cultura que nos envolve e também em nossa interioridade. As crianças e jovens que circulam nas escolas de hoje são sujeitos forjados no interior dessa cultura do consumismo, do descarte, da espetacularização das mídias. Quando esses jovens seres chegam à escola já estão inteiramente capturados pelas malhas do consumo. De acordo com Costa (2009, p. 77-78):

O alfabetismo dirigido ao consumo inicia-se já em casa, em frente à televisão e nos teclados dos computadores. O marketing televisivo começa a operar suas pedagogias de sedução e deleite para formar clientes quando estes ainda usam fraldas. Por sua vez, e a seu tempo, fantásticas e solitárias viagens virtuais levam as crianças ainda pequenas a passear por verdadeiros impérios mercantis, onde operações financeiras são trivializadas e convertidas em passes de mágica: desejou, comprou! Antes das crianças entrarem na escola, as corporações empresarias já fizeram seu trabalho. Às escolas parece caber apenas administrar estes eus transbordantes de desejos supérfluos, inebriantes, descartáveis e infinitamente renováveis. Mais do que uma difícil tarefa, eis um novo e imenso desafio que se apresenta às professoras e aos professores destes tempos - enfrentar o consumismo e educar o consumidor-cidadão .

\section{Forjando os sujeitos que vão à escola}

Passo então a expor e comentar algumas pesquisas que analisam aquilo que, lá dentro da escola, nos aponta para fora dela. Todas estas análises delinearam-se no âmbito das pesquisas já mencionadas sobre a entrada da cultura pós-moderna na escola (COSTA, 2004, 2007). 


\section{Há uma infância pós-moderna na escola}

Tomando a infância como uma construção cultural, social e histórica sujeita a mudanças, e considerando as condições contemporâneas marcadas pela cultura pós-moderna, o estudo de Momo (2007) pretende mostrar que, com implicações contundentes da mídia e do consumo, configura-se hoje uma infância que coloca sob tensão as imagens convencionais e modernas de infância com que muitos professores persistem trabalhando. Um dos objetivos foi dar visibilidade às crianças pobres que frequentam algumas escolas no município de Porto Alegre nesse início do século XXI, e realizar uma das leituras possíveis de como os sujeitos infantis das escolas estudadas vivem a infância sob as condições culturais pós-modernas. $\mathrm{O}$ estudo mostra, como novos modos de ser criança e de viver a infância, são engendrados e governam a vida das crianças pobres das escolas estudadas; todas elas crianças produzidas, formatadas, fabricadas pela cultura da mídia e do consumo.

O corpus de análise montado para viabilizar as conexões entre as crianças das escolas e a cultura pós-moderna incluiu artefatos que integram a cultura circulante da mídia e do consumo, como reportagens, comunicações publicitárias, imagens de crianças, diferentes produtos direcionados à infância, etc. Um inventário de artefatos e práticas evidentes nas escolas foi realizado mediante registros fotográficos, anotações em diário de campo, conversas com crianças e professoras, bem como foram coletados desenhos e textos produzidos em sala de aula. O conjunto dos materiais coletados dentro e fora das escolas ajudou a autora a compor e a expor um panorama das condições culturais pós-modernas, e contribuiu para o objetivo de mostrar uma infância pós-moderna que vai à escola hoje.

Nos resultados do estudo ficou evidente a consonância entre as formas como essas crianças pobres vivem a infância e constituem-se como alunos e as configurações culturais do mundo contemporâneo. Visibilidade, efemeridade, ambivalência, fugacidade, descartabilidade, individualismo, superficialidade, instabilidade, fazem parte de suas vidas. Observou-se crianças que buscam infatigavelmente a fruição e o prazer e, nessa busca, aparecem borradas as fronteiras de classe, gênero e geração. Há um modo de ser criança, incansavelmente desejoso por inscrever-se na cultura globalmente reconhecida e integrar uma comunidade de consumidores de artefatos em voga na mídia do momento. Observou-se a espetacularização dos corpos infantis de modo a harmonizá-los com o mundo das visibilidades, caracterizado por constantes e ininterruptas mutações. São crianças que vão se tornando o que são, vivendo sob a condição pós-moderna (MOMO; COSTA, 2009). 
A investigação alerta para o fato de que tais crianças desestabilizam as pedagogias, causam inquietação, pois já não é mais possível classificá-las, cartografá-las ${ }^{10}$, enquadrá-las nos lugares tradicionalmente designados para infantis e para escolares. São polivalentes, podendo ser de diferentes e distintas formas ao mesmo tempo e, no momento seguinte, já possuírem outras formas, antes mesmo que seja possível conhecê-las e apreendê-las. Crianças pós-modernas são um desafio para a educação escolarizada porque não permitem o estabelecimento de uma ordem e a elaboração de planos a longo prazo.

\section{O telefone celular reconfigurando a infância e a vida escolar}

No mundo pós-moderno, em que os modos de vida são crescentemente governados pela cultura midiática e tecnológica, que institui valores, preferências e gostos, o telefone celular surge como um dos artefatos centralmente implicados nas configurações da infância. Ele tem sido um artefato polêmico na vida das crianças porque vem modificando suas relações na escola, na família e entre elas mesmas. Além disso, tem ajudado a fortalecer uma visão de infância que a posiciona como "poderosa" e "superinteligente". Surge uma infância de crianças espertas, empreendedoras, crescentemente fascinadas, engendradas e capturadas pela tecnologia. O estudo de Born (2006) problematizou as repercussões do telefone celular na vida das crianças das sociedades do início do século XXI, com interesse especial por suas repercussões na escola, um espaço tradicional que vai sendo modificado pela entrada de novos sujeitos infantis e novos artefatos e produtos da indústria cultural.

A autora voltou-se para o celular procurando discutir como ele surge e se inscreve no cenário contemporâneo em meio a um aparato de marketing que a todos envolve, irrecorrivelmente, percorrendo todas as camadas sociais, impondo-se e aderindo a todos os estilos e modos de vida. O objetivo central do trabalho foi tentar mostrar como o celular tem contribuído para modificar o comportamento e orientar a conduta de vida das crianças dentro e fora da escola. Além disso, apontou para algumas estratégias utilizadas pelas crianças como forma de resistência ao controle adulto e buscou evidências da transformação das relações que o uso desta tecnologia desencadeia, e como isso tem interferido no currículo e nas práticas escolares.

10 Um estudo de Costa (2008) aborda essa questão relativamente a jovens contemporâneos que frequentam as escolas. 
Os resultados sublinharam as ambivalências desse artefato, que ao mesmo tempo em que possibilita às crianças a criação de um mundo independente e particular, expõe-nas a constantes controles e vigilância. Esses, no entanto, sujeitos a frequentes burlas mediante divertidas e inconsequentes estratégias de, simultaneamente, escapar e expor-se ao olhar dos adultos. Por uma outra face, a posse desse artefato pode significar tanto o pertencimento a uma comunidade, como, paradoxalmente, uma exacerbação da individualidade. Contudo, isolando ou "enturmando", o estudo apontou para uma mudança nas relações interpessoais, onde a presença material, física, os contatos face a face ou pele a pele parecem ser tão efetivos quanto a presença virtual ou a "tele-presença". A investigação também indicou que as interações mediadas pelo uso do telefone celular começam a repercutir na linguagem oral e escrita das crianças, aparentemente inibindo a oralidade por um lado, mas por outro criando e disseminando novos códigos para a linguagem escrita. De fato observa-se a composição de um universo alheio e à prova de adultos, bem como de outros alienígenas nesse novo universo de práticas e significados.

Born (2006) levanta a hipótese de que o uso do celular não estaria somente modificando as relações pessoais, como também interfere diretamente no currículo escolar. As novas linguagens e códigos de escrita, além de alterarem as habilidades das crianças, causam um certo desconforto entre as professoras, que perdem pontos de contato com as crianças. O celular é um artefato que repercute não apenas em questões disciplinares e de comunicação, mas aponta para a necessidade de ingerências na seleção de conteúdos curriculares e nas práticas pedagógicas de sala de aula.

\section{Aprende-se a consumir com Três Espiãs Demais}

Dentre os inumeráveis programas assistidos por crianças das séries iniciais, uma professora pesquisadora identificou a preferência pela série de desenho animado Três Espiãs Demais e elegeu-a para objeto de estudo. O objetivo foi refletir a partir das narrativas apresentadas em dezesseis episódios da série, quais representações de jovens meninas eram colocadas em destaque, quais atitudes eram narradas como naturais e "normais". A pesquisa de Ignácio (2007) procurou chamar a atenção para a forma como esse desenho animado compõe as identidades de jovens meninas contemporâneas, apresentando-as como inteiramente capturadas pela cultura do consumo. O eixo da análise foi o consumo - um conceito que durante a assistência e decupagem dos episódios 
começou a esboçar-se para a pesquisadora como chave, como central, para poder discutir, problematizar e mostrar a produtividade do artefato cultural examinado no governo da conduta das crianças, especialmente de algumas jovens meninas que vão à escola hoje. Os resultados apontaram para um jeito que se distingue, e muito, daqueles dos séculos XIX e XX. Moda, consumo e namorados descartáveis apresentam-se como temas preferenciais no dia a dia das jovens meninas contemporâneas expostas no desenho.

O estudo evidenciou, também, o desenho animado operando uma pedagogia que ensina às jovens meninas os meandros e estratégias do consumismo. Os resultados mostraram as narrativas dos episódios construídas sobre uma representação de tempo e espaço pós-modernos - volátil, alucinante - em que as meninas espiãs apresentam-se compulsivamente voltadas ao consumo de objetos de aparências e de relacionamentos.

A obsessão pelo corpo perfeito, as estratégias para conquista de status social e o imperativo de ter ao lado um jovem estonteantemente belo, fazem de seu dia a dia um constante desejar e descartar objetos da moda em evidência na sociedade do espetáculo. Numa estratégia discursiva que ao mesmo tempo em que exorta parece também caricaturizar e colocar sob crítica a superficialidade e a banalidade de suas escolhas, ações e condutas, o desenho apresenta as missões de caráter coletivo-mundial, a serem levadas à efeito pelas meninas, niveladas com as de caráter individual-grupal.

O que chama a atenção é que, em meio à ludicidade e ao prazer do entretenimento, as narrativas do desenho animado Três espiãs demais invadem a vida de crianças e jovens, convocando-os a compartilhar significados sobre o mundo do consumo, exposto em práticas que os enquadram e acomodam nas lógicas das sociedades orientadas pelo e para o mercado.

\section{O complexo Rebelde enredando sujeitos nas teias do consumo}

Em direção semelhante àquela da pesquisa de Ignácio (2007), o estudo relizado por Flor (2007) dedica-se à análise dos circuitos e teias do que o autor denominou Complexo Rebelde, um conglomerado de entretenimento que aciona uma imensa rede de produtos que exercem imenso fascínio sobre crianças e jovens. Operando com as metáforas de circuitos e teias, o pesquisador mostra como opera o Complexo na convocação para o consumo. De uma novela de televisão - Rebelde -, na qual nasce uma banda que circula permanentemente entre a ficção do folhetim e os shows ao vivo lotados de fãs, emerge a energia 
do Complexo que se mantém vivo por aproximadamente dois anos, produzindo uma fantástica proliferação de artefatos que invadem a vidas de crianças e jovens, visíveis em seus corpos (adereços de todo o tipo) e em suas atividades de lazer e entretenimento. Da mesma forma como jornais e revistas noticiaram o fenômeno Rebelde, sua presença nas escolas e sua fantástica posição no ranking dos sites mais consultados do Google, as escolas também experimentaram a ascensão e o declínio da verdadeira febre midiática em que o mesmo se converteu.

Os resultados do estudo revelaram que o Complexo perpassou a sociedade como um todo. As fulgurações do circuito encantaram crianças, jovens, pais, mães e avós, e suas teias os enredaram no consumo de Cds da Banda, Dvds das temporadas da novela, e mercadorias de todo o tipo, de brincos, tênis e uniformes a estilos de cabelo, álbuns, figurinhas, diários e cadernos. As professoras chegaram a organizar suas aulas em conformidade com os temas abordados pelas novelas. O idioma espanhol podia ser ouvido diariamente nas aulas e nas festinhas de aniversário, com o fundo musical das músicas da Banda RBD. Sem dúvida, uma fantástica pedagogia cultural, acionada por prazer, fascínio, sedução e deleite.

\section{O complexo W.I.T.C.H formando garotinhas nas redes do consumo}

No âmbito desses estudos que investigam os complexos formados por redes e estratégias de mercantilização, a pesquisa de Prates (2008) volta-se para um programa de TV e uma revista de variedades intitulados W.I.T.C.H, que vêm colocando em circulação uma infinidade de artefatos correlatos, por esse motivo também denominados pela pesquisadora de Complexo W.I.T.C.H. Os dados coletados permitiram vislumbrar o fascínio que o Complexo provoca, cativando e envolvendo jovens meninas, principalmente convocando-as para o consumo de artigos esotéricos e iniciando-as em práticas desse tipo. A investigação focaliza esse processo de enredamento das jovens meninas pelo Complexo W.I.T.C.H. $\mathrm{O}$ estudo indica que ao mesmo tempo em que as jovens meninas se interessam pelo tema do desenho animado e da revista, vão moldando suas condutas de acordo com os preceitos, regras, receitas, etc., que circulam em todo o complexo, e sendo dirigidas para o consumo.

O estudo mostrou que todo o Complexo W.I.T.C.H. - revistas, livros secretos (um tipo interessante de manual de autoajuda), diário, brindes, como pedras e amuletos, e diversos outros artefatos - nada mais é do que uma estratégia de indução ao consumo acionada pelo fascínio, pela magia. Um bem urdido 
aparato de tecnologias psi, presente nas estratégias mercantis do Complexo, leva as meninas a investirem em cuidados de si, engajando-se nas tecnologias da subjetividade a que se referem muitos dos autores contemporâneos dedicados ao estudo dos processos de subjetivação. O Complexo W.I.T.C.H. ensina as jovens garotas a interessarem-se por questões relacionadas à beleza, à autoestima e ao amor, bem como a exercitarem-se em práticas nessa mesma direção. Elas aprendem táticas para vestir-se de acordo com padrões propostos pelo Complexo e, sobretudo, de acordo com os gostos dos meninos. O complexo ensina as meninas a lidarem com seus sentimentos, emoções, situações cotidianas que circundam a família, a escola, os amigos e os amores. Tudo isso a partir das fórmulas mágicas, dos testes, das matérias propostas nas revistas, bem como através das lições, ensinamentos e recomendações expressos nos Livros Secretos. Cada uma das jovens garotas acaba aprendendo e agindo sobre si mesma de uma certa forma, pois recebem e interpretam essas lições de modos diferentes, conforme a pesquisadora pode perceber em diferentes momentos e conversas que manteve com suas interlocutoras. Implícita e explicitamente, porém, o Complexo convoca o tempo todo as jovens garotas para o consumo.

\section{Análises culturais e formação de professores}

O sempre crescente número de análises do que Camozzatto (2010) denomina de pedagogias do presente - essas novas formas de dirigir as condutas que se esboçam em meio às tramas das imagens e do consumo - já configura um substantivo arcabouço teórico disponível para se repensar a formação de professores para as sociedades do século XXI. Ainda outros objetos de estudo podem ser acrescentados àqueles que compõem a amostra eletiva que aqui apresentei. A tese de Tomazzoni dos Santos (2009) surpreende-nos ao mostrar as "lições de dança" levadas a efeito pela mídia como um dispositivo pedagógico acionado na formação de sujeitos. $\mathrm{O}$ autor identifica e demonstra em operação dez lições que se esboçam para configurar sujeitos dançantes em políticas de gestão da vida. Administram-se sujeitos, promovendo o gerenciamento de singularidades e a potencialização de novos modos de ser e estar no mundo. Outra aproximação instigante do campo educacional verifica-se em tese que estuda os discursos sobre educação nas revistas Veja, Época e IstoÉ (GERZSON, 2007).

A autora considera a mídia como dispositivo da governamentalidade neoliberal na medida em que faz proposições para as sociedades contemporâ- 
neas, sugerindo concepções e práticas de educação favoráveis à manutenção das políticas neoliberais. Nos textos das revistas, as expectativas atribuídas à educação atendem às demandas de preparar os estudantes para a produtividade máxima no mercado de trabalho. A educação é encarregada de cumprir com sua parte para o "desenvolvimento", tendo como base "o sucesso" dos sujeitos. Por sua vez, um estudo sobre animes japoneses (MARCON, 2010), entre outros achados, aborda a produtividade dessa manifestação da cultura pop na constituição de certo tipo de estudantes dedicados e estudiosos que despontam nas salas de aula. E ainda outro estudo, que interessa particularmente à formação de professores, trata das representações de escola em um conjunto de quatro filmes de animação que trazem cenas escolares em suas tramas (ORTIZ, 2008) e ensinam como a escola funciona. Os resultados desta pesquisa indicaram que as aulas das escolas dos filmes de animação são "enfadonhas", desqualificando sua função na cultura e na vida das crianças. A escola é representada como uma instituição que não atende às necessidades dos alunos, não propicia divertimento, prazer e interesse. Os filmes analisados ensinam ainda que as crianças devem ir para a escola, não para aprender alguma coisa com os professores, mas para relacionar-se com os colegas.

Como se pode constatar, o campo da Formação de Professores está desafiado por um considerável conjunto de estudos atuais, que ajudam a desenhar os novos contornos da vida nas sociedades de hoje e oferecem contribuições substantivas e consistentes para se pensar a educação sob novos ângulos e perspectivas, para além dos limites exclusivamente escolares.

Conforme tenho argumentado, antes de ingressar na escola, as pedagogias do presente, forjadas na condição pós-moderna, já se encarregaram do alfabetismo requerido para que as crianças dominem a gramática cultural do nosso tempo. Elas chegam à escola fascinadas por imagens, espetáculo e consumo, já familiarizadas com o ritmo vertiginoso dos acontecimentos e com a curta duração, volatilidade e descartabilidade dos objetos, das experiências, dos desejos, dos sentimentos. Pautam suas vidas pela urgência, rapidez e imediatismo (comidas instantâneas, conexão com o mundo num clicar de teclado, novas roupas, afetos e estilos a qualquer momento), e reinventam seus eus inspiradas em repertórios identitários infinitamente renovados. São essas crianças nascidas no século XXI que frequentam nossas salas de aula. Sabemos quem elas são? Como se tornaram o que são? O que elas precisam aprender que ainda não sabem? Como se educa quando é difícil vislumbrar uma direção desejável?

Como afirma Ramos do Ó (apud RAMOS do Ó; COSTA, 2007, p. 110), hoje convivemos e somos capazes de compreender as ambivalências, ambiguidades e contradições que perpassam os diversos domínios da vida política, social e econômica, e isso marca nossas vidas e nossa identidade. Contudo, segundo 
ele, embora a escola já tenha mudado, ainda parece haver um desencontro, uma vez que a escola parece refletir pouco sobre as mudanças em curso hoje:

[...] ela continua a funcionar a partir de idéias claras e distintas sobre o que é certo e errado. A noção de fronteira, tendo em vista o estabelecimento definitivo da verdade, está na base da escola que todos conhecemos. O modelo de educação que nós temos está mais perto do século XIX do que do século atual. E os alunos que nós temos, evidentemente, são mais do século XXI do que do século XIX.

Os diversos estudos que procurei aqui apresentar brevemente sugerem ser uma tarefa árdua essa de pensar em uma escola para sociedades tão complexas e plurifacetadas, em um tempo em que tudo é líquido, volátil e efêmero, conforme nos ensina Bauman (2007). Nossa experiência do espaço e do tempo encontra-se alterada, e isso configura uma condição crítica para uma instituição inventada para ajudar a edificar o mundo da ordem, da longa duração, das coisas certas, das ideias claras e distintas. Algumas discussões atuais tem cobrado da escola uma maior abertura aos modos de ser contemporâneos, às novas formas de vida. E se a escola ainda se mantém quase impermeável às mudanças, isso talvez possa ser atribuído em grande proporção às lacunas na formação de professores, que tem encontrado empecilhos para articular-se dentro desse espírito dos novos tempos, e dar conta, dentre outros imperativos, do que Williams $(1961,1969)$ e outros denominam de mudanças na "estrutura do sentimento". Talvez, como argumenta Ramos do Ó (apud RAMOS do Ó; COSTA, 2007, p. 112), “os professores pudessem deixar de ser mensageiros da verdade, e dedicarem-se, junto com seus alunos, à construção de representações do mundo, a partir das intermináveis apreensões, interpretações, reinvenções possíveis". As linguagens aportadas hoje pelas novas tecnologias viabilizam, segundo esse estudioso da escola, complexos jogos de identidade, sendo a identidade pessoal uma construção inacabada e o eu um "projeto marcado por múltiplas trajetórias" (RAMOS do Ó, apud RAMOS do Ó; COSTA, 2007, p.114). E de acordo com Costa (apud RAMOS do Ó; COSTA, 2007, p. 114), as novas tecnologias, com todo o aparato discursivo que comportam, são "uma espécie de produtoras da subjetividade. De novos jeitos de ser sujeito. Novas formas de viver, novas formas de ser pessoa humana".

Encaminho-me para o final desse texto, invocando mais uma vez o acima mencionado diálogo entre Ramos do Ó e Costa (2007, p. 115), em que o autor afirma: 
O modelo escolar que começa no final do século XIX é um modelo muito baseado no princípio da homogeneidade. Embora se fale muito na diferença da criança, que cada criança é uma criança, você tem todo um currículo escolar que está desenhado para a construção de grupos de alunos muito idênticos. O professor se acostumou a dirigir-se ao que ele pensa ser o aluno médio. Portanto, você tem por um lado uma forte pressão sobre as crianças para se "normalizarem" e, por outro lado, princípios de forte estigmatização. E essa estigmatização é tão importante porque ela leva o princípio da "normalização" e atinge áreas muito diferentes. Você pode ter muito valor no plano da sua inteligência, mas se não for bonito ou autocontrolado não terá sucesso. Nós estamos a construir, em nome dessa homogeneidade de que ninguém fala, crianças com muito sofrimento e uma fortíssima vigilância face a um padrão normal.

Finalizando este artigo, declaro que ao me dedicar à sua composição, pretendi, sobretudo, apontar para alguns estudos que analisam e discutem variadas faces da vida e distintas formas de educar e educar-se nas sociedades do século XXI. Pensei, com isso, chamar a atenção para análises culturais que, do meu ponto de vista, poderiam contribuir de forma significativa para aproximar a Formação de Professores das questões centrais desses novos tempos com suas múltiplas, complexas, divergentes e sempre renovadas demandas.

\section{REFERÊNCIAS}

BAUMAN, Zygmunt. O mal-estar da pós-modernidade. Tradução de: GAMA, Mauro, GAMA, Claudia. Rio de Janeiro: Jorge Zahar, 1998.

BAUMAN, Zygmunt. Globalização: as conseqüências humanas. Tradução: PENCHEL, Marcus. Rio de Janeiro: Jorge Zahar, 1999.

BAUMAN, Zygmunt. Modernidade líquida. Tradução de: DENTZIEN, Plínio. Rio de Janeiro: Jorge Zahar, 2001.

BAUMAN, Zygmunt. Tempos líquidos. Tradução de: MEDEIROS, Carlos Alberto. Rio de Janeiro: Jorge Zahar, 2007.

BAUMAN, Zygmunt. Vida para consumo. Tradução de: MEDEIROS, Carlos Alberto. Rio de Janeiro: Zahar, 2008. 
BORN, Lilian Ivana. O telefone celular e algumas repercussões nos modos de vida da infância e na vida escolar. Dissertação (Mestrado em Educação) - ULBRA, PPGEDU, Canoas, 2006.

BORTOLAZZO, Sandro Faccin. Vivendo no espetáculo, aprendendo com o espetáculo - cultura rave e a produção de jovens contemporâneos. Dissertação (Mestrado em Educação) - ULBRA, PPGEDU, Canoas, 2010.

CAMOZZATTO, Viviane. Da pedagogia às pedagogias - formas, ênfases e transformações. Projeto de Tese de (Doutorado) - UFRGS, PPGEDU, Porto Alegre, 2010.

COSTA, Marisa Vorraber; SILVEIRA, Rosa Hessel; SOMMER, Luis Henrique. Estudos Culturais, Educação e Pedagogia. Revista Brasileira de Educação. Número Especial - Cultura, Culturas e Educação. n. 23, maio/jun./jul./ago. 2003.

COSTA, Marisa Vorraber; CAMOZZATTO, Viviane Castro. O magistério nas novelas da TV. In: COSTA, Marisa Vorraber (Org.). O Magistério na Política Cultural. Canoas: Ed. Ulbra, 2006. p. 235-264.

COSTA, Marisa Vorraber; MOMO, Mariangela. A conveniência da escola. Revista Brasileira de Educação, Campinas, Autores Associados, v. 14, n. 42, set./dez. 2009.

COSTA, Marisa Vorraber. Ensinando a dividir o mundo; as perversas lições de um programa de televisão. Revista Brasileira de Educação, n. 20, maio/jun./jul./ago. 2002.

COSTA, Marisa Vorraber. Quando o pós-moderno invade a escola: um estudo sobre novos artefatos, identidades e práticas culturais. Projeto de pesquisa apoiado pelo CNPq. (2004-2007), 2004.

COSTA, Marisa Vorraber. Consumo, mídia e espetáculo na cena pedagógica investigando relações entre escola e cultura contemporânea. Projeto de pesquisa apoiado pelo CNPq (2007-2010), 2007.

COSTA, Marisa Vorraber. Cartografando a gurizada da fronteira: novas subjetividades na escola. In: ALBUQUERQUE JÚNIOR, Durval; VEIGA-NETO, Alfredo; SOUSA FILHO, Alípio (Orgs.). Cartografias de Foucault. Belo Horizonte: Autêntica, 2008. p. 269-294.

COSTA, Marisa Vorraber. (Org.). A Educação na Cultura da Mídia e do Consumo. Rio de Janeiro: Lamparina, 2009.

COSTA, Marisa Vorraber. Sobre educação e cultura do consumo. In: COSTA, Marisa Vorraber. (Org.). A educação na cultura da mídia e do consumo. Rio de Janeiro: Lamparina, 2009a. p. 22-37. 
COSTA, Andresa Silva da. O dispositivo de racionalização da pobreza nas pedagogias contemporâneas: um estudo das representações dos sem-terra nos livros didáticos de história. Dissertação (Mestrado em Educação) - ULBRA, PPGEDU, Canoas, 2009.

FLOR, Douglas Moacir. A convocação para o consumo nas pedagogias culturais circuitos e teias do Complexo Rebelde. Dissertação (Mestrado em Educação) - ULBRA, PPGEDU, Canoas, 2007.

GARCIA-CANCLINI, Nestor. Consumidores e cidadãos: conflitos multiculturais da globalização. 6 ed. Rio de Janeiro: Editora UFRJ, 2006.

GERZSON, Vera Serezer. A mídia como dispositivo da governamentalidade neoliberal - os discursos sobre educação nas revistas Veja, Época e Isto é. Tese (Doutorado em Educação) - UFRGS, PPGEDU, Porto Alegre, 2007.

GIROUX, Henry. Cruzando as fronteiras do discurso educacional: novas políticas em educação. Tradução de: LOPES, Magda França. Porto Alegre: Artes Médicas, 1999.

GIROUX, Henry. Atos impuros. A prática política dos estudos culturais. Tradução de: COSTA, Ronaldo. Porto Alegre: Artmed, 2003.

HALL, Stuart. A centralidade da cultura: notas sobre as revoluções culturais do nosso tempo. Educação \& Realidade, v. 22, n. 2, jul./dez., 1997.

HARVEY, David. Condição Pós-Moderna: uma pesquisa sobre as origens da mudança cultural. Tradução de: SOBRAL, Adail; GONÇALVES, Maria Estela. São Paulo: Loyola, 1993.

HUYSSEN, Andreas. Mapeando o pós-moderno. In: BUARQUE DE HOLLANDA, Heloisa (Org.). Pós-Modernismo e Política. Rio de Janeiro: Rocco, 1992.

IGNÁCIO, Patrícia. Aprendendo a consumir com Três Espiãs Demais. Dissertação de Mestrado (Educação) - ULBRA, PPGEDU, Canoas, 2007.

JAMESON, Fredric. Pós-Modernismo. A lógica cultural do capitalismo tardio. Tradução de: CEVASCO, Maria Elisa. São Paulo: Ática, 1996.

LÉVY, Pierre. As tecnologias da inteligência. Tradução de: COSTA, Carlos Irineu da. Rio de Janeiro: Editora 34, 1996.

LYOTARD, Jean-François. A condição Pós-Moderna. 5 ed. Tradução de: MIRANDA, José Bragança de. Lisboa: Gradiva, s/d.

MARCON, Carla Simone Corrêa. O Universo Anime na produção de jovens otakus que vão à escola. Dissertação (Mestrado em Educação) - ULBRA, PPG, Canoas, EDU, 2010. 
MOMO, Mariângela. Mídia e consumo na produção de uma infância pós-moderna que vai à escola. Tese (Doutorado em Educação) - UFRGS, PPGEDU, Porto Alegre, 2007.

MOMO, Mariangela; COSTA, Marisa Vorraber. Crianças que vão à escola no início do século XXI - elementos para se pensar uma infância pós-moderna. In: 32 REUNIÃO ANUAL DA ANPED, 32., Caxambu, 2009.

ORTIZ, Paula Nunes. A escola nas tramas da linguagem e da cultura: um estudo sobre filmes de animação. Dissertação (Mestrado em Educação) - ULBRA, PPGEDU, Canoas, 2008.

PRATES, Camille Jacques. O Complexo W.I.T.C.H. acionando a magia para formar garotinhas nas redes do consumo. Dissertação (Mestrado em Educação) - ULBRA, PPGEDU, Canoas, 2008.

PROTAS, Tânia Regina Veloso. Sujeitos líquidos em trânsito nas narrativas contemporâneas - um estudo sobre motobóis e pedagogias culturais. Dissertação (Mestrado em Educação) - ULBRA, PPGEDU, Canoas, 2009.

RAMOS do Ó, Jorge; COSTA, Marisa Vorraber. Desafios à escola contemporânea: um diálogo. Educação \& Realidade, v. 32, n. 2, p. 109-116, jul. dez. 2007.

SARLO, Beatriz. Cenas da vida pós-moderna.Tradução de: ALCIDES, Sergio. Rio de Janeiro: Editora da UFRJ, 1997.

SENNET, Richard. A Corrosão do Caráter. Conseqüências pessoais do trabalho no novo capitalismo. Tradução de: SANTARRITA, Marcos. 6 Ed. Rio de Janeiro: Record, 2002.

SENNET, Richard. A cultura do novo capitalismo. Tradução de: MARQUES, Clovis. Rio de Janeiro: Record, 2006.

STEINBERG, Shirley; KINCHELOE, Joe L. Sem segredos: cultura infantil, saturação de informação e infância pós-moderna. In: STEINBERG, Shirley; KINCHELOE, Joe L. (Orgs.). Cultura Infantil - a construção corporativa da infância. Rio de Janeiro: Civilização Brasileira, 2001.

TOMAZZONI DOS SANTOS, Airton. Lições de dança no baile da pós-modernidade: corpos (des)governados na mídia. Tese (Doutorado em Educação) - UFRGS, PPGEDU, Porto Alegre, 2009.

WILLIAMS, Raymond. Cultura e Sociedade. Tradução de: HEGENBERG, Leônidas; MOTA, Octanny Silveira da; TEIXEIRA, Anísio. São Paulo: Companhia Editora Nacional, 1969.

WILLIAMS, Raymond. The Long Revolution. Harmondsworth: Penguin, 1961. 
YÚDICE, George. A conveniência da cultura: usos da cultura na era global. Tradução de: KREMER, Marie-Anne. Belo Horizonte: Editora UFMG, 2004.

Texto recebido em 3 de fevereiro de 2010.

Texto aprovado em 27 de fevereiro de 2010. 